\section{Case Reports in Gastroenterology}

Case Rep Gastroenterol 2021;15:443-449

DOI: $10.1159 / 000514542$

Published online: April 28, 2021

(C) 2021 The Author(s)

Published by S. Karger AG, Basel

www.karger.com/crg

This article is licensed under the Creative Commons Attribution-NonCommercial 4.0 International License (CC BY-NC) (http://www.karger.com/Services/OpenAccessLicense). Usage and distribution for commercial purposes requires written permission.

\title{
Biliary Sphincter of Oddi Dysfunction
}

\author{
Asim Haider ${ }^{a} \quad$ Ayesha Siddiqa $^{a} \quad$ Nisha Ali $^{a} \quad$ Shehriyar Mehershahi ${ }^{a, b}$ \\ a Internal Medicine, BronxCare Health System, Bronx, NY, USA; ${ }^{b}$ Gastroenterology, \\ BronxCare Health System, Bronx, NY, USA
}

\begin{abstract}
Sphincter of Oddi dysfunction (SOD) is a syndrome caused by either dyskinesia or stenosis of the sphincter of Oddi. It has been categorized into biliary and pancreatic SOD based on clinical features and laboratory findings. We present a case of a 51-year-old female (postcholecystectomy) who presented with intermittent chronic right upper quadrant pain. Laboratory investigations showed persistently elevated liver function tests and a dilated common bile duct without the presence of any stones. Endoscopic retrograde cholangiopancreatography with manometry showed an elevated sphincter of Oddi pressure, thus confirming the diagnosis of SOD. She underwent endoscopic sphincterotomy and papillotomy with normalization of liver function tests and resolution of her chronic symptoms.

(C) 2021 The Author(s)

Published by S. Karger AG, Basel
\end{abstract}

\section{Introduction}

The sphincter of Oddi is composed of small circular and longitudinal muscular segments that are mostly contained within the wall of the duodenum. The term sphincter of Oddi dysfunction (SOD) is a clinical syndrome of pancreatic or biliary obstruction due to functional or mechanical abnormalities of the sphincter of Oddi. The terms sclerosing papillitis, biliary spasm, papillary stenosis, biliary dyskinesia, and postcholecystectomy syndrome have been

Asim Haider
Department of Internal Medicine
BronxCare Health System
1650 Grand Concourse, Bronx, NY 10457 (USA)
ahaider@bronxcare.org




\section{Case Reports in Gastroenterology}

\begin{tabular}{l|l}
\hline Case Rep Gastroenterol 2021;15:443-449 \\
\hline DOI: 10.1159/000514542 & $\begin{array}{l}\text { @ 2021 The Author(s). Published by S. Karger AG, Basel } \\
\text { www.karger.com/crg }\end{array}$ \\
\hline
\end{tabular}

Haider et al.: Biliary Sphincter of Oddi Dysfunction

used synonymously with SOD. Two different entities are widely recognized based upon their distinct mechanisms; (a) sphincter of Oddi stenosis, (b) sphincter of Oddi dyskinesia. The term SOD encompasses both sphincter of Oddi stenosis and sphincter of Oddi dyskinesia. Sphincter of Oddi stenosis is an anatomical disorder associated with narrowing of the sphincter of Oddi. The underlying pathology is usually inflammation or scarring, which could be due to various causes, including infection, trauma (usually intraoperative), pancreatitis, the passage of a gallstone through the papilla, and adenomyosis. Sphincter of Oddi dyskinesia is a functional disturbance of the sphincter of Oddi, leading to intermittent biliary obstruction. The cause of the sphincter of Oddi dyskinesia is not well understood. Studies suggest that the spasm may be influenced by local hormonal or neurologic disturbance.

\section{Case Presentation}

A 51-year-old female with no significant medical history presented to the emergency department with complaints of intermittent right upper quadrant abdominal pain. She reported that the pain was dull, intermittent (lasting for 20-30 min each time), and has been there for a few months. She denied any nausea, vomiting, fever, change in bowel habits, unintentional weight loss, or loss of appetite. She underwent cholecystectomy a year back. She denied any history of toxic habits, including alcohol abuse. Physical examination revealed a non-tender, non-distended abdomen with normal bowel sounds. Her initial labs, including complete blood count with differentials, erythrocyte sedimentation rate, basic metabolic profile, prothrombin time, partial thromboplastin time, international normalized ratio, amylase, lipase, and creatinine phosphokinase, were normal. Liver function tests showed alanine aminotransferase of 662 units/L (normal range: 5-40 units/L), aspartate aminotransferase of 857 units/L (normal range: 9-36 units/L), alkaline phosphatase of 261 units/L (normal range: 53-141 units/L), total bilirubin of $1.6 \mathrm{mg} / \mathrm{dL}$ (normal range: $0.2-1.2 \mathrm{mg} / \mathrm{dL}$ ), and conjugated bilirubin of 1.4 (normal range: $0.1-0.3 \mathrm{mg} / \mathrm{dL}$ ). Autoimmune workup, hepatitis serology, serum ceruloplasmin levels, celiac panel, and alpha- 1 antitrypsin levels were normal (see Table 1 for detail).

Transabdominal ultrasound showed a $7.0 \mathrm{~mm}$ common bile duct without any evidence of common bile duct stone or mass (Fig. 1). A magnetic resonance cholangiopancreatography abdomen did not show any common bile duct stone. An endoscopic ultrasound (EUS) of the upper gastrointestinal tract showed a dilated common bile duct to $7.3 \mathrm{~mm}$ without the presence of any stones (Fig. 2). There was no endoscopic abnormality in the pancreas or pancreatic duct. Due to persistent symptoms and elevated liver function tests, she underwent endoscopic retrograde cholangiopancreatography with manometry, which revealed an elevated biliary sphincter phasic pressure of 80, which confirmed the diagnosis of SOD. Endoscopic sphincterotomy and papillotomy were performed. Following surgery, the patient's symptoms gradually resolved, and liver function test normalized.

\section{Karger'=}




\section{Case Reports in Gastroenterology}

\begin{tabular}{l|l}
\hline Case Rep Gastroenterol 2021;15:443-449 \\
\hline DOI: 10.1159/000514542 & $\begin{array}{l}\text { (c) 2021 The Author(s). Published by S. Karger AG, Basel } \\
\text { www.karger.com/crg }\end{array}$ \\
\hline
\end{tabular}

Haider et al.: Biliary Sphincter of Oddi Dysfunction

\section{Discussion/Conclusion}

SOD includes two different clinical syndromes: biliary pain and idiopathic recurrent acute pancreatitis. Biliary SOD is common in patients who undergo cholecystectomy (hence it is also known as postcholecystectomy syndrome). The underlying pathophysiology is not clear, but it is proposed that the gallbladder serves as a reservoir to off-load increased pressure in the common bile duct occurring during sphincter spasm, and its removal leads to the unmasking of preexisting SOD [1]. Another possible explanation is that there is the alteration of the sphincter of Oddi motility because of the severing of nerve fibers that pass between the gallbladder and the sphincter of Oddi via the cystic duct [2]. However, SOD has also been observed in patients with intact gallbladders, which suggests that some other process may be involved [3]. Biliary colic-type pain without other apparent causes suggests SOD. The pain is usually located in the right upper abdomen or epigastrium and lasts from 30 minutes to several hours [4]. Characteristics that are not suggestive of biliary SOD include lancinating pain that lasts for seconds, constant pain that lasts all day, pain exacerbated by eating, pain relieved by defecation, or pain associated with diarrhea. The pain is also not relieved by anticholinergic antispasmodics, antacids, $\mathrm{H} 2$-blockers, or proton pump inhibitors.

Idiopathic recurrent acute pancreatitis is defined as two or more attacks of well-documented acute pancreatitis of unclear cause despite an exhaustive workup (laboratory and noninvasive imaging) with complete resolution of clinical and laboratory findings between attacks. SOD is one of the most common diagnoses found in patients with idiopathic recurrent acute pancreatitis. In an illustrative report, SOD was noted in 41 of 126 patients (33\%) who underwent endoscopic retrograde pancreatography with sphincter of Oddi manometry [5]. Patients with pancreatic SOD present with recurrent episodes of pancreatitis. The episodes typically occur months apart and are associated with elevations in the amylase and lipase. Liver transaminases and bilirubin may also be elevated, and there may be dilation of the pancreatic duct.

The approach to a patient with suspected SOD depends upon the patient's clinical presentation and the results of laboratory testing and abdominal imaging. In general, only patients fulfilling the Rome IV criteria should undergo invasive evaluation for SOD [6]. This decreases patients' chance of being inappropriately subjected to invasive testing for SOD that is associated with significant complications (primarily pancreatitis). Biliary SOD may be suspected based upon the presence of biliary-type pain, abnormal liver tests (aminotransferases, alkaline phosphatase, or bilirubin more than two times normal values) that normalize between attacks, and dilation of the common bile duct. The Milwaukee classification of biliary SOD divides the condition into three subtypes based on the presence of abnormal liver tests and a dilated common bile duct [7]. (a) Type I included patients with biliary-type abdominal pain, with all of the altered liver enzymes on blood testing, and dilated biliary ducts. These patients do not require additional testing and should be referred directly for endoscopic retrograde cholangiopancreatography with endoscopic sphincterotomy. (b) Type II is characterized by biliary-type abdominal pain along with either altered liver enzymes on blood testing or dilated biliary ducts on imaging tests. Such patients should undergo sphincter of Oddi manometry to confirm the diagnosis. (c) Biliary-type pain in the absence of biliary duct alteration and normal 


\section{Case Reports in Gastroenterology}

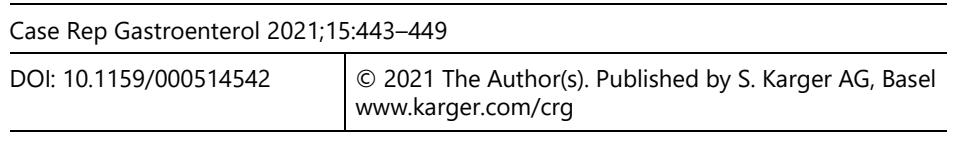

Haider et al.: Biliary Sphincter of Oddi Dysfunction

liver functions tests was the so-called type III biliary SOD. Such patients may have symptoms due to functional biliary type pain or other functional bowel diseases, such as dyspepsia or irritable bowel syndrome.

Transabdominal ultrasound should be performed to evaluate the anatomy of the common bile duct. However, common bile duct dilation ( $>6 \mathrm{~mm}$ ) may be observed in up to one-third of patients after cholecystectomy [8]. Also, the size of the common bile duct may increase with age [9]. As a result, dilation of the common bile duct alone is insufficient evidence for establishing the diagnosis of SOD. It should be considered in the context of symptoms, liver, and pancreatic biochemical tests. Several provocation tests have been developed to increase the specificity of common bile duct diameter measurement for determining SOD that uses either a fatty meal (fatty meal ultrasonography) or cholecystokinin to increase bile flow. In patients who have a normal sphincter of Oddi function, the bile duct diameter does not change or remains constant after stimulation; an increase of more than $2 \mathrm{~mm}$ is considered pathological [10]. Hepatobiliary scintigraphy using technetium-99m labeled dyes can also provide an assessment of delayed biliary drainage in patients whose gallbladder is absent [11]. However, it may be falsely positive in patients who have biliary obstruction from various causes, or it may be falsely negative in patients who have sphincter of Oddi dyskinesia in whom the obstruction to bile flow may be intermittent.

Sphincter of Oddi manometry remains the gold standard for diagnosing SOD. Patients with stenosis are identified by an abnormally elevated basal sphincter of Oddi pressure $(>40$ $\mathrm{mm} \mathrm{Hg}$ ), which is the most widely clinically accepted diagnostic finding for SOD. This finding is reproducible, and the elevated sphincter of Oddi pressure does not relax following the administration of smooth muscle relaxants. On the other hand, patients with sphincter of Oddi dyskinesia may also have elevated basal sphincter of Oddi pressure. However, in contrast to the sphincter of Oddi stenosis, the elevated pressure decreases dramatically following the administration of smooth muscle relaxants.

In conclusion, SOD is a clinical syndrome caused by either dyskinesia or stenosis of the sphincter of Oddi. Clinicians should keep it as a differential diagnosis in patients presenting with recurrent intermittent right upper quadrant pain after cholecystectomy, especially in the setting of elevated liver enzymes. Only carefully selected patients should undergo an invasive evaluation to decrease the chance of being inappropriately subjected to invasive testing for SOD that is associated with significant complications.

\section{Statement of Ethics}

Written informed consent was obtained from the patient for publication of this case report and any accompanying images.

\section{Conflict of Interest Statement}

None to declare.

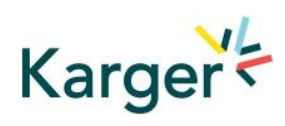




\section{Case Reports in Gastroenterology}

\section{Funding Sources}

None to declare.

\section{Author Contributions}

All authors certify that he or she has participated sufficiently in the intellectual content, the analysis of data. Each author has reviewed the final version of the manuscript and approves it for publication. Should the editors request the data upon which the work is based, the authors shall produce it.

\section{References}

1 Lisbona R. The scintigraphic evaluation of sphincter of Oddi dysfunction. J Nucl Med. 1992 Jun;33(6):12234.

2 Luman W, Williams AJ, Pryde A, Smith GD, Nixon SJ, Heading RC, et al. Influence of cholecystectomy on sphincter of Oddi motility. Gut. 1997 Sep;41(3):371-4.

3 Choudhry U, Ruffolo T, Jamidar P, Hawes R, Lehman G. Sphincter of Oddi dysfunction in patients with intact gallbladder: therapeutic response to endoscopic sphincterotomy. Gastrointest Endosc. 1993 JulAug;39(4):492-5.

4 Baillie J. Sphincter of Oddi dysfunction: overdue for an overhaul. Am J Gastroenterol. 2005 Jun;100(6):121720.

5 Kaw M, Brodmerkel GJ Jr. ERCP, biliary crystal analysis, and sphincter of Oddi manometry in idiopathic recurrent pancreatitis. Gastrointest Endosc. 2002 Feb;55(2):157-62.

6 Cotton PB, Elta GH, Carter CR, Pasricha PJ, Corazziari ES. Rome IV. Gallbladder and Sphincter of Oddi Disorders. Gastroenterology. 2016 Feb 19:S0016-5085(16)00224-9. doi: https://doi.org/10.1053/j.gastro.2016.02.033. Epub ahead of print. PMID: 27144629.

7 Behar J, Corazziari E, Guelrud M, Hogan W, Sherman S, Toouli J. Functional gallbladder and sphincter of oddi disorders. Gastroenterology. 2006 Apr;130(5):1498-509.

8 Hunt DR, Scott AJ. Changes in bile duct diameter after cholecystectomy: a 5-year prospective study. Gastroenterology. 1989 Dec;97(6):1485-8.

9 Kaim A, Steinke K, Frank M, Enriquez R, Kirsch E, Bongartz G, et al. Diameter of the common bile duct in the elderly patient: measurement by ultrasound. Eur Radiol. 1998;8(8):1413-5.

10 Fein AB, Rauch RF 2nd, Bowie JD, Halvorsen RA Jr, Rosenberg ER. Intravenous cholecystokinin octapeptide: its effect on the sonographic appearance of the file ducts in normal subjects. Radiology. 1984 Nov;153(2):499-501.

11 Sostre S, Kalloo AN, Spiegler EJ, Camargo EE, Wagner HN Jr. A noninvasive test of sphincter of Oddi dysfunction in postcholecystectomy patients: the scintigraphic score. J Nucl Med. 1992 Jun;33(6):1216-22. 


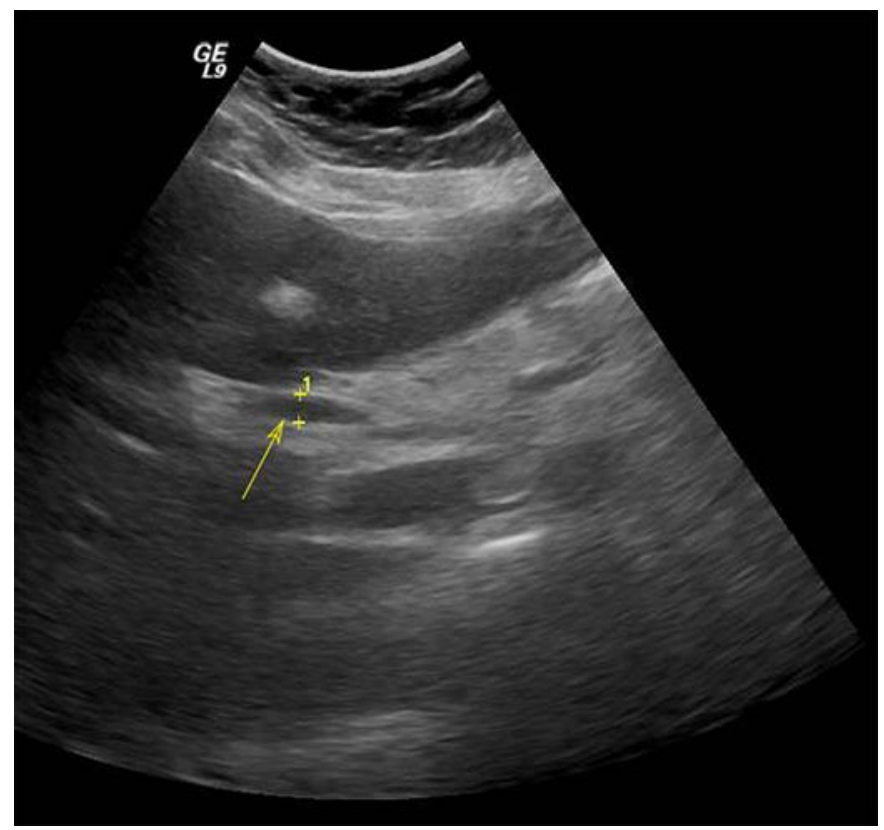

Fig. 1. Transabdominal ultrasound showing dilated common bile duct.

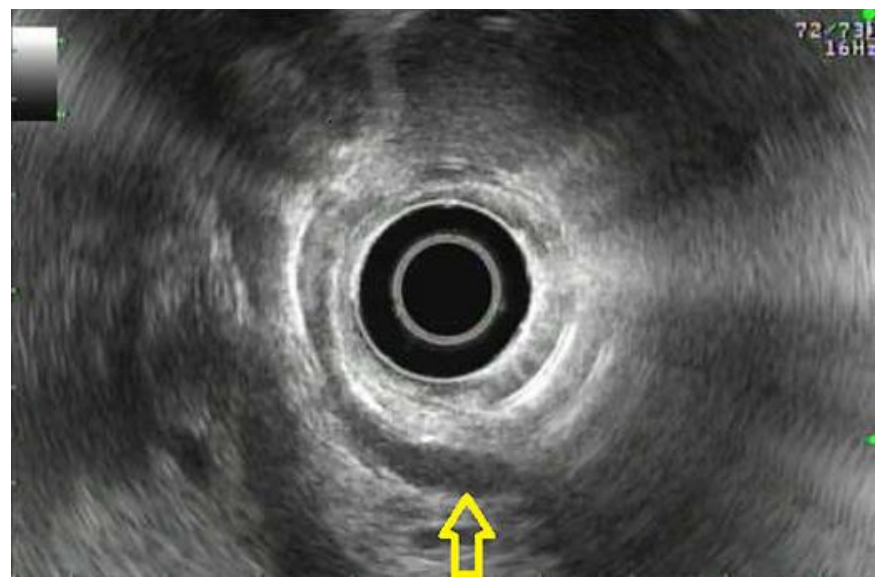

Fig. 2. Endoscopic ultrasound of upper gastrointestinal tract showing dilated common bile duct. 
Case Reports in Gastroenterology
Case Rep Gastroenterol 2021;15:443-449 www.karger.com/crg
w 2021 The Author(s).

Haider et al.: Biliary Sphincter of Oddi Dysfunction

Table 1. Pertinent laboratory results

\begin{tabular}{ll}
\hline Test & Result \\
\hline Hemoglobin $(12-16 \mathrm{~g} / \mathrm{dL})$ & 12.5 \\
WBC $\left(4.8-1.8 \times 10^{3} / \mu \mathrm{L}\right)$ & 7.5 \\
BUN $(8-26 \mathrm{mg} / \mathrm{dL})$ & 7 \\
Creatinine $(0.5-1.5 \mathrm{mg} / \mathrm{dL})$ & 0.7 \\
Protein, serum $(6-8.5 \mathrm{~g} / \mathrm{dL})$ & 6.5 \\
Albumin, serum $(3.4-4.8 \mathrm{~g} / \mathrm{dL})$ & 3.5 \\
ALT $(5-40$ units/L) & 662 \\
AST (9-36 units/L) & 857 \\
ALP (53-141 units/L) & 261 \\
GGT (8-54 units/L) & 717 \\
tTG antibodies & Negative \\
Ceruloplasmin $(18-36 \mathrm{mg} / \mathrm{dL})$ & 35 \\
Hepatitis A IgM & Negative \\
Hepatitis Be antigen & Negative \\
Hepatitis Be antibody & Negative \\
Hepatitis Bs antigen & Negative \\
Hepatitis C & Negative \\
HIV antibody & Negative \\
Tylenol (10-30 $\mu$ g/mL) & $<10$ \\
ANA & Negative \\
ASMA & Negative \\
AMA & Negative \\
Anti-LKM-1 & Negative \\
\hline
\end{tabular}

WBC, white blood cells; BUN, blood urea nitrogen; ALT, alanine transaminase; AST, aspartate aminotransferase; GGT, gammaglutamyl transferase; tTG, tissue transglutaminase; ANA, antinuclear antibody; ASMA, anti-smooth muscle antibody; AMA, antimitochondrial antibodies; Anti-LKM-1, liver kidney microsome type 1 antibodies. 